\title{
Physician Attitudes and Beliefs Associated with Patient Pneumococcal Polysaccharide Vaccination Status
}

\author{
Tammy A. Santibanez, PbD \\ Richard Kent Zimmerman, \\ $M D, M P H^{1,2}$
}

Mary Patricia Nowalk, PbD, RD ${ }^{1}$

Ilene Katz Jewell, MS Hyg ${ }^{2}$

Inis J. Bardella, $M D^{1}$

'Department of Family Medicine and Clinical Epidemiology, School of Medicine, University of Pittsburgh, Pittsburgh, Pa

${ }^{2}$ Department of Behavioral and Community Health Sciences, Graduate School of Public Health, University of Pittsburgh, Pittsburgh, $\mathrm{Pa}$
Conflicts of interest: none reported

\section{CORRESPONDING AUTHOR}

Richard Kent Zimmerman, MD, MPH

Department of Family Medicine and Clinical Epidemiology

University of Pittsburgh School of Medicine 3518 Fifth Ave

Pittsburgh, PA 15261

zimmer@pitt.edu

\begin{abstract}
BACKGROUND Barriers to adult immunizations persist as current rates for pneumococcal polysaccharide vaccine (PPV) receipt among eligible adults remain below national goals. This study investigated potential barriers to patients receiving the PPV, including predisposing, enabling, environmental and reinforcing factors among physicians from a variety of practice and geographic settings.
\end{abstract}

METHODS Participants were 60 primary care physicians from inner-city, rural, suburban, and Veterans Affairs practices, which included adults aged 65 years and older. Elderly patients able to complete a telephone interview were randomly selected from each physician's practice.

RESULTS Self-reported PPV vaccination status was significantly related to physician report of routinely providing PPV to their patients and to the practice providing immunization clinics or other immunization promotion programs. Physicians who were highly unlikely to refer uninsured adults to health departments for immunizations had a significantly higher percentage of patients reporting receipt of PPV $(P=.03)$.

CONCLUSIONS Enabling and environmental factors related to physicians, such as economic and insurance issues, were significant barriers to PPV vaccination. Vaccination rates might be improved through efforts that reduce likelihood of referral for immunizations and office systems that support immunization, such as patient and provider reminders and express vaccination clinics.

Ann Fam Med 2004;2:41-48. DOI: 10.1370/afm.53.

\section{INTRODUCTION}

$\mathrm{P}$ ublic health and medical communities have long preferred primary prevention of disease to secondary or tertiary prevention because it is frequently more cost-effective, both in terms of human suffering and economic burden. The case for prevention is especially compelling for a disease with high mortality rates or one that requires only a single behavioral intervention, such as vaccination, rather than long-term lifestyle changes. Invasive pneumococcal disease is a prime example. Pneumonia and influenza together are the fifth leading cause of death in the elderly (65 years and older) in the United States. ${ }^{1}$ Although invasive pneumococcal disease is effectively prevented through a single vaccination, vaccination rates are low compared with national goals. In the first quarter of 2002 , only $55 \%$ of all elderly persons reported receiving pneumococcal polysaccharide vaccine (PPV). ${ }^{2}$ Despite national campaigns to increase vaccination rates, Medicare reimbursement for the cost of pneumococcal vaccination, and wide dissemination of vaccine usage guidelines, the Healthy People 2010 immunization goal, set at $90 \%,{ }^{3}$ remains elusive. Clearly, there are factors that inhibit PPV use among adult populations. 
Previous research has identified system, patient, and provider barriers to vaccination. In the past, barriers to PPV have been the cost of vaccine and lack of national regulations allowing standing orders for vaccination of inpatients. Medicare reimbursement for the cost of pneumococcal vaccination should have eliminated this economic barrier, and changes in Medicare regulations allowing standing orders for adult immunizations have been recently published. ${ }^{4}$ We have previously found that patient barriers to vaccination include lack of awareness of PPV recommendations and not knowing that Medicare pays for the vaccine. ${ }^{5,6}$ Vaccination was more common among patients who believed in the efficacy of the vaccine, had no concerns about it, and believed that their physicians, relatives, and friends recommended pneumococcal immunization. ${ }^{6}$

Others have shown that physician recommendation is a key factor in improving PPV rates. ${ }^{7}$ Physician barriers include uncertainty of PPV status and concerns about vaccine efficacy in immunocompromised patients, among other barriers. ${ }^{8}$ The purpose of this study was to examine further those clinician factors that affect PPV rates among a diverse sample of physicians from rural, suburban, Veterans Affairs (VA), and inner-city practices.

Examination of a behavior that is influenced by physician, patient, and system factors requires a comprehensive model. We chose the PRECEDE-PROCEED framework $^{9}$ as the theoretical basis for associating physician factors with the behavior of interest, ie, vaccination. The PRECEDE-PROCEED framework includes the concepts of predisposing factors, such as concerns about side effects; reinforcing factors, such feedback on immunization rates; enabling factors, such as reminders; and environmental factors, such as vaccine cost (Figure 1). Within this framework, we also used components of the awareness-to-adherence model, ${ }^{10}$ which was developed specifically to explain physician use of immunization guidelines. This model consists of several sequential cognitive and behavioral steps: (1) those initially unaware of a guideline must first become aware of it, (2) they then must intellectually agree with it, (3) then they must adopt it in practice, and finally (4) they routinely follow or adhere to it. This framework and model integration allowed us to incorporate physician behaviors as well as office system interventions, such as standing orders to vaccinate all eligible patients.

\section{METHODS}

Practices, physicians, and patients were selected from 4 strata to include a broad spectrum of older adult patients and vaccination policies.

\section{Physician Subjects}

The 4 strata were (1) rural medical practices and (2) urban-suburban (suburban) medical practices in a network of nonacademic practices affiliated with the University of Pittsburgh Medical Center (UPMC) in Western and Central Pennsylvania, (3) outpatient clinics in VA health centers, and (4) inner-city neighborhood health centers in Pittsburgh.

Random samples of practices were selected in the large rural and suburban UPMC strata, and all of the practices were selected in the smaller, inner-city and VA strata. The eligibility criterion for individual physicians was having a practice consisting of greater than $50 \%$ primary care patients. All eligible physicians in each practice were included, which resulted in a sample of 8 rural practices with 15 physicians, 9 suburban practices with 19 physicians, 3 VA practices with 16 physicians, and 4 inner-city practices with 15 physicians.

\section{Patient Subjects}

A random sample of elderly patients was selected for each clinician using billing lists with a target of 15 completed patient interviews per clinician. Patient inclusion criteria were age of 66 years or older, an office visit after September 30,1998, and ability to complete a study interview in English or Spanish. Patients who were homeless, residing in nursing homes, or not currently living in the region, and those who were deaf, had severe psychosis, or dementia were excluded.

\section{Questionnaires}

\section{Physician Questionnaires}

Physician surveys incorporated factors from the PRECEDE-PROCEED framework and the awareness-toadherence model. There were 2 physician questionnaires, a self-administered questionnaire, and a personal interview conducted by trained interviewers. The focus of the self-administered questionnaire was on the office culture, including preventive services, the physician's role in the practice, personal health habits, and beliefs regarding adult immunizations as factors potentially affecting immunization practices. It consisted of 160 questions, primarily closed-ended, with some opportunities for individual elaboration. The focus of the personal interview was specific aspects of adult immunization practices, including the physician's perception of patient factors that might affect immunization behaviors. The interview consisted of approximately 60 questions, both open- and closed-ended. Responses to open-ended questions were grouped and coded by researchers experienced in this technique. Physicians were offered a $\$ 150$ honorarium for participation. 


\section{Figure 1. Factors included in the PRECEDE-PROCEED framework.}

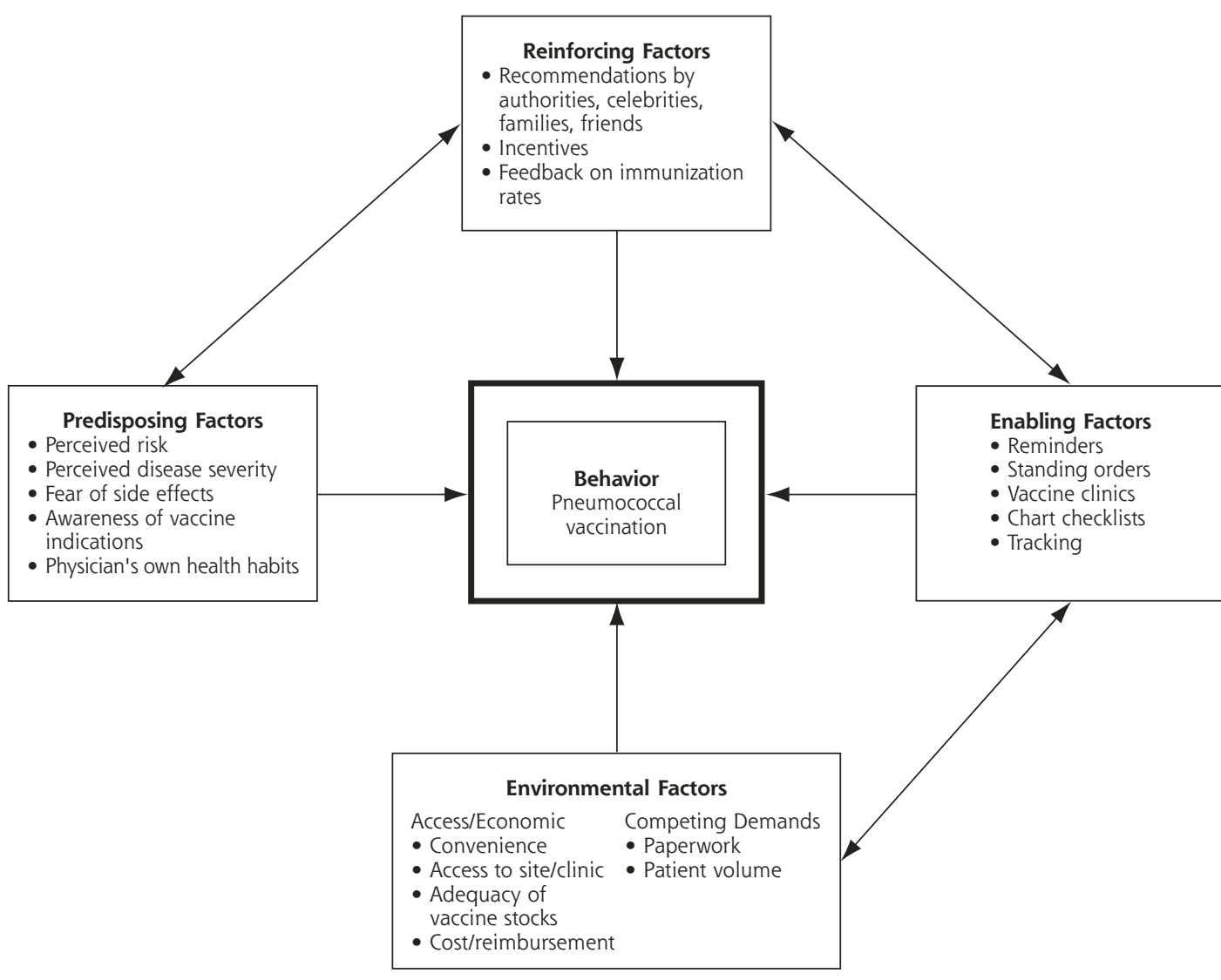

\section{Patient Questionnaire}

Although the patient questionnaire included many questions, the only question used in this analysis was self-reported PPV status, which serves as the main outcome variable. Results regarding the remaining patient questionnaire variables have been reported elsewhere. ${ }^{11}$

\section{Data Collection}

For the 2 physician surveys, agreement by individual physicians to participate was understood when the practice agreed to participate. Trained interviewers made appointments to visit or call the physicians at a time convenient to them. The interviews took approximately 30 minutes. Self-administered questionnaires and a stamped return envelope were given to physicians at the time of the interview. Interviews and survey completion took place from August 1999 through February 2000.

An introductory letter from the principal investigator and an endorsement letter from the patient's clinician were sent to each patient. Patients were offered an honorarium to complete the interview. Computerassisted telephone interviewing permitted direct data entry during the interview. ${ }^{12}$ Telephone interviews were conducted by trained personnel from April 17, 2000, to October 27, 2000, with most interviews completed during the summer. A detailed description of the methods used in this study has been published. ${ }^{13}$

This project was approved by the Institutional Review Board of the University of Pittsburgh and the Human Subjects Use Subcommittee of the Institutional Review Board of the VA Healthcare System of Pittsburgh.

\section{Statistical Methods}

We utilized SUDAAN software (RTI, Research Triangle, NC), which is designed for the analysis of complex survey data. Analyses were weighted to account for the unequal patient selection probabilities. Closed-ended questions included some that required rating responses on Likert scales; for analysis, responses were collapsed into categories as appropriate. (For example, for some questions, approximately one half of respondents answered " 0 " with the remainder distributed among " 1 " through "10." Responses were dichotomized accordingly.) Chi-square tests were used to compare patients who received PPV with those who did not, with regard to physician and practice characteristics. 
Logistic regression analysis was performed to determine variables significantly associated with patient receipt of the pneumococcal vaccination. All variables significant at $P<.10$ in bivariate analyses with the outcome variable were included in a forward selection procedure.

\section{RESULTS}

\section{Response Rate}

Sixty-one physicians completed both the interview and self-administered questionnaire. One physician was found to be ineligible because he was solely hospital-based and could not have knowledge of specific office systems. This resulted in a $92 \%$ response rate (60 of 65). Interviews were available for 925 patients of these physicians. Small sample sizes in each stratum precluded meaningful analyses of data by stratum.

\section{Demographics}

Physician demographics are shown in Table 1. Most of the physicians were white men; however, there was a good representation of women and minorities. Physicians represented a broad range of ages, years in practice, and practice types, as was intended in the study design. Patient demographic characteristics have been published elsewhere. ${ }^{11}$ The patient pneumococcal immunization rate was $67 \%$.

\section{Delivery of Pneumococcal Vaccination}

All physicians reported recommending PPV to their patients, and most physicians $(83 \%)$ reported recommending tetanus and diphtheria toxoids. More than two thirds of the physicians $(67 \%)$ estimated that $70 \%$ or more of their patients routinely receive the PPV once at age 65 years. This response was significantly associated with patient self-reported vaccination status; among these physicians, $73 \%$ of patients reported receiving the PPV compared with $60 \%$ of patients whose physicians reported that less than $70 \%$ of their patients routinely received the PPV $(P=.015)$.

In an open-ended question as to what situations prompted revaccination with PPV, 23\% reported revaccinating if the first dose had been given before the age of 65 years, $58 \%$ reported revaccinating if previous vaccination had been in the distant past, and $36 \%$ reported revaccinating if the patient had an immunocompromising disease or was at risk (total was more than 100\% because more than 1 response could be given). A scenario was described of a 65 -year-old patient with chronic obstructive pulmonary disease who was vaccinated at age 60 years with PPV. Four fifths ( $81 \%$ ) of the physicians recommended revaccination with $\mathrm{PPV}_{i}$ this finding was not associated with patient pneumococcal vaccination status.

\section{The PRECEDE-PROCEED Framework for Predicting Pneumococcal Vaccination Status}

Predisposing and reinforcing factors were not significantly associated with PPV status. Almost all physicians $(95 \%)$ reported that pneumococcal vaccination was important for asymptomatic elderly patients, and most physicians rated a low likelihood of adverse effects from PPV, with 69\% rating minor side effects as unlikely and $97 \%$ rating serious side effects as unlikely. Of the many predisposing and reinforcing factors examined, such as financial incentives, personal or family experience with immunizations, sources of immunization information (national policy-making organizations, colleagues, etc), none was associated with PPV rates.

On the other hand, enabling and environmental factors, eg, those related to the office setting and procedures, were significantly associated with PPV status. Approximately one half of the physicians $(45 \%, \mathrm{n}=$ 27 ) reported that their practice has an immunization clinic or other specific program to enhance immunization. Having such a program was associated with patient receipt of PPV. Among physicians with pro-

\begin{tabular}{|lc|}
\hline Table 1. Physician and Practice & Characteristics \\
\hline Characteristic & Response No. (\%) \\
\hline Stratum* & \\
Inner-city & $15(25)$ \\
Rural & $14(23)$ \\
Suburban & $19(32)$ \\
Veterans Affairs & $12(20)$ \\
Race (white) & $49(83)$ \\
Sex (female) & $20(33)$ \\
Medical school graduation year & $(1954-1997)$ \\
(median, range) & \\
Age, years (median, range) & $42(26-72)$ \\
Distance to primary admitting hospital & \\
$<1$ mile & $22(37)$ \\
1-10 miles & $31(53)$ \\
$>10$ miles & $6(10)$ \\
Usual number of patient office hours & $30(8-50)$ \\
per week (median, range) & \\
Practice employs registered nurses & $42(71)$ \\
Nursing assistance & \\
Share designated nurse & $12(22)$ \\
Do not share designated nurse & \\
Nurses not designated & \\
Evening office hours offered & \\
Weekend office hours offered & \\
Practice educates medical or other & \\
students, residents or fellows & \\
\hline \multirow{2}{*}{ questionnaire data. } & \\
\hline
\end{tabular}




\section{Table 2. Enabling and Environmental Factors Related to Patient Pneumococcal Vaccination (PPV) Status}

\begin{tabular}{|c|c|c|c|c|c|}
\hline \multirow[b]{2}{*}{ PRECEDE-PROCEED Factor } & \multirow{2}{*}{$\begin{array}{c}\text { Physician } \\
\text { Responses } \\
\text { No. (\%) }\end{array}$} & \multicolumn{3}{|c|}{ Patient PPV Status } & \multirow[b]{2}{*}{$\begin{array}{c}P \\
\text { Value }\end{array}$} \\
\hline & & No. & $\begin{array}{l}\text { Vaccinated } \\
(\%)\end{array}$ & $\begin{array}{l}\text { Unvaccinated* } \\
(\%)\end{array}$ & \\
\hline \multicolumn{6}{|l|}{ Enabling factor } \\
\hline \multicolumn{6}{|l|}{$\begin{array}{l}\text { Office promotes influenza vaccination } \\
\text { through patient education efforts }\end{array}$} \\
\hline Yes & $27(45)$ & 419 & 62 & 38 & .035 \\
\hline No & $33(55)$ & 506 & & & \\
\hline \multicolumn{6}{|l|}{$\begin{array}{l}\text { Office promotes influenza vaccination } \\
\text { through flu shot clinics }\end{array}$} \\
\hline Yes & $23(38)$ & 369 & 77 & 23 & .011 \\
\hline No & $37(62)$ & 556 & & & \\
\hline \multicolumn{6}{|l|}{$\begin{array}{l}\text { Office promotes influenza vaccination } \\
\text { through patient reminders }\end{array}$} \\
\hline Yes & $9(16)$ & 145 & 86 & 14 & .030 \\
\hline No & $49(84)$ & 747 & 66 & 34 & \\
\hline \multicolumn{6}{|l|}{$\begin{array}{l}\text { Office promotes pneumococcal } \\
\text { vaccination through provider } \\
\text { reminders }\end{array}$} \\
\hline Yes & $20(33)$ & 311 & 77 & 23 & .031 \\
\hline No & $40(67)$ & 614 & 63 & 37 & \\
\hline \multicolumn{6}{|c|}{$\begin{array}{l}\text { Office promotes immunization through } \\
\text { immunization clinics or other specific } \\
\text { program }\end{array}$} \\
\hline Yes & $27(45)$ & 411 & 76 & 24 & .037 \\
\hline No & $33(55)$ & 514 & 63 & 37 & \\
\hline \multicolumn{6}{|l|}{ Environmental factor - economic ${ }^{\dagger}$} \\
\hline \multicolumn{6}{|c|}{$\begin{array}{l}\text { Refer adult without any insurance who } \\
\text { is unable to pay to health department }\end{array}$} \\
\hline Very unlikely & $14(24)$ & 220 & 82 & 18 & .050 \\
\hline Somewhat unlikely to very likely & $4(76)$ & 690 & 64 & 36 & \\
\hline \multicolumn{6}{|l|}{$\begin{array}{l}\text { Refer adult with Medicaid coverage to } \\
\text { health department }\end{array}$} \\
\hline Very unlikely & $27(46)$ & 416 & 76 & 24 & .019 \\
\hline Somewhat unlikely to very likely & $32(54)$ & 494 & 62 & 38 & \\
\hline \multicolumn{6}{|c|}{$\begin{array}{l}\text { Refer adult }>65 \text { years with Medicare to } \\
\text { health department }\end{array}$} \\
\hline Very unlikely & $32(54)$ & 499 & 73 & 27 & .072 \\
\hline Somewhat unlikely to very likely & $27(46)$ & 411 & 62 & 38 & \\
\hline \multicolumn{6}{|l|}{$\begin{array}{l}\text { Refer adult with commercial insurance } \\
\text { that pays for immunization to health } \\
\text { department }\end{array}$} \\
\hline Very unlikely & $33(56)$ & 494 & 76 & 24 & .012 \\
\hline Somewhat unlikely to very likely & $26(44)$ & 416 & 60 & 40 & \\
\hline \multicolumn{6}{|l|}{$\begin{array}{l}\text { Refer adult with commercial insurance } \\
\text { that does not pay for immunization } \\
\text { to health department }\end{array}$} \\
\hline Very unlikely & $17(29)$ & 268 & 78 & 22 & .029 \\
\hline Somewhat unlikely to very likely & $42(71)$ & 642 & 63 & 37 & \\
\hline \multicolumn{6}{|l|}{$\begin{array}{l}\text { Environmental factor - competing } \\
\text { demands }\end{array}$} \\
\hline \multicolumn{6}{|l|}{ Satisfaction with managing practice } \\
\hline Dissatisfied & $9(16)$ & 142 & 74 & 26 & .033 \\
\hline Intermediate & $28(48)$ & 423 & 60 & 40 & \\
\hline Satisfied & $21(36)$ & 328 & 73 & 27 & \\
\hline \multicolumn{6}{|l|}{ Bothered by stress at work } \\
\hline Never & $14(24)$ & 207 & 54 & 46 & .030 \\
\hline Intermediate & $23(40)$ & 363 & 74 & 26 & \\
\hline Always & $21(36)$ & 324 & 67 & 33 & \\
\hline
\end{tabular}

grams, $76 \%$ of their patients reported a pneumococcal vaccination, whereas among those without such programs, $63 \%$ of their patients reported PPV receipt $(P=$ .031). Physicians in practices with systems in place to promote influenza vaccination, pneumococcal vaccination, and immunizations in general had greater numbers of patients who received a pneumococcal vaccination. Patients of physicians who reported that their offices offered immunization clinics or who used patient reminders about influenza vaccines and provider chart reminders about pneumococcal vaccines had higher pneumococcal vaccination rates than patients whose physicians did not report these practices (Table 2).

Environmental factors were divided into access or economic and competing demands factors. Physicians were asked how concerned they were about the amount of reimbursement paid by Medicare for vaccine injection; overall, 30\% were not at all concerned (rating 0 ), $48 \%$ had little to no concern (rating 1 through 5), and $22 \%$ were somewhat to very concerned (rating 6 through 10). Physician concern about Medicare reimbursement for vaccine injection was not significantly associated with patient pneumococcal vaccination status.

Physicians were asked to report their likelihood of referring adults to the health department for immunizations in a number of scenarios, ranging from patients having no insurance to having insurance, commercial 
or otherwise, that pays for adult immunizations. Vaccination status was significantly related to physician's likelihood to refer. Physicians who were very unlikely to refer their patients to the health department had significantly higher percentages of patients reporting PPV receipt (Table 2 ).

There were no differences in pneumococcal vaccination rates between physicians who thought that referring an adult patient to the health department for vaccination would likely delay vaccination or inconvenience the patient and those physicians who did not.

Physicians were asked how much time and energy (none, some, a lot) was demanded by several patient care-related activities. "A lot" of time and energy was reported by $80 \%$ of physicians for charting medical records, $64 \%$ of physicians for follow-up of abnormal laboratory tests and radiographs, $63 \%$ of physicians for patient telephone calls, $24 \%$ of physicians for organizing referrals, and $19 \%$ of physicians for insurance-related forms and telephone calls. Spending a lot of time at these activities, however, was not related to patient vaccination rates.

Among the vaccinated patients, $45 \%$ had physicians who reported being very satisfied with the management aspect of their jobs, whereas among the unvaccinated patients only $35 \%$ had physicians who were very satisfied $(P=.03)$. Thirty-five percent of physicians reported always being bothered by stress at work, and this finding was significantly associated with vaccination status of patients. Of physicians never bothered by stress and hassles at home or work, $54 \%$ of their patients were vaccinated compared with $74 \%$ among those with intermediate stress and $67 \%$ among those reporting to be always stressed $(P=.03)$.

\section{Multivariable Regression Analyses}

From the forward selection logistic regression analyses, the odds of receiving PPV were significantly higher among patients whose physicians were less likely to refer Medicaid patients to the health department for immunizations, physicians who deemed such referral to be an inconvenience to patients, physicians who had not received complaints from patients after an influenza vaccination, and physicians who believed that most of their patients had received a pneumococcal vaccination. Patients of physicians who reported never being bothered by stress and hassles at home or work had lower odds of being vaccinated (Table 3 ).

\section{DISCUSSION}

Using the PRECEDE-PROCEED framework, we were able to assess the effects of various factors on pneumococcal vaccination behavior. We detected barriers to adult pneumococcal immunization that differed from those described by the awareness-to-adherence model

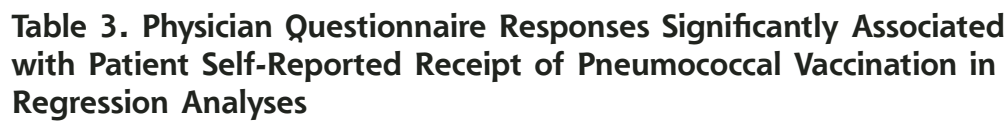

\begin{tabular}{|c|c|c|}
\hline Physician Factors & $\begin{array}{l}\text { Adjusted } \\
\text { Odds Ratio } \\
(95 \% \mathrm{Cl})\end{array}$ & $P$ Value \\
\hline \multicolumn{3}{|c|}{$\begin{array}{l}\text { Likelihood to refer an adult with commercial insurance } \\
\text { that pays for immunization to the health department } \\
\text { for immunizations }\end{array}$} \\
\hline Very unlikely & $1.78(1.49,2.14)$ & $<.001$ \\
\hline Unlikely to very likely & referent & \\
\hline \multicolumn{3}{|c|}{$\begin{array}{l}\text { Has received complaints from patients following } \\
\text { influenza vaccination }\end{array}$} \\
\hline Yes & $0.57(0.45,0.73)$ & $<.001$ \\
\hline No & referent & \\
\hline \multicolumn{3}{|c|}{$\begin{array}{l}\text { Estimated percentage of patients }>65 \text { years that receive } \\
\text { pneumococcal vaccine in your practice }\end{array}$} \\
\hline $0 \%-70 \%$ & $0.53(0.42,0.67)$ & $<.001$ \\
\hline$>70 \%$ & referent & \\
\hline \multicolumn{3}{|c|}{ I am bothered by stress and hassles at work } \\
\hline Never & $0.35(0.23,0.54)$ & $<.001$ \\
\hline Intermediate & $0.93(0.74,1.16)$ & \\
\hline Always & referent & \\
\hline \multicolumn{3}{|c|}{$\begin{array}{l}\text { For the patient, convenience of referral to the health } \\
\text { department for vaccination }\end{array}$} \\
\hline No inconvenience & $0.69(0.55,0.87)$ & .003 \\
\hline Major inconvenience & referent & \\
\hline \multicolumn{3}{|c|}{$\begin{array}{l}\text { Office has very effective mechanisms to ensure } \\
\text { continuity of care }\end{array}$} \\
\hline Strongly disagree & $1.05(0.63,1.74)$ & .004 \\
\hline Neutral & $0.64(0.47,0.89)$ & \\
\hline Strongly agree & referent & \\
\hline \multicolumn{3}{|c|}{$\begin{array}{l}\text { Physician satisfaction with inpatient care aspect of } \\
\text { practice }\end{array}$} \\
\hline Very dissatisfied & $1.33(0.96,1.83)$ & .03 \\
\hline Intermediate & $1.37(1.07,1.75)$ & \\
\hline Very satisfied & referent & \\
\hline
\end{tabular}

Note: All variables that had $P<.10$ in bivariate analyses with the dependent variable were entered into the forward selection logistic regression. 
for immunization behaviors. Because most physicians in our study reported routinely providing PPV to most of their eligible older patients, it appears that these physicians are not only aware of the vaccine and agree with recommendations for its use, they have also adopted and adhere to the recommendations. We found that vaccinated patients were more likely to be from practices that enabled physicians to provide immunizations more easily-immunization promotion programs, immunization clinics, provider reminders such as chart prompts, and patient reminders such as mailed postcards. These services are clear indications that a practice has adopted and adheres to recommendations.

The other physician factors contributing to patient receipt of PPV vaccination were environmental, ie, economic considerations and competing demands of the practice. Patients were more likely to report receiving PPV if their physician was unlikely to refer patients to the health department for immunizations. Physicians of vaccinated patients were less likely to refer patients who did not have third party payment for vaccines than were physicians of unvaccinated patients; that is, if patients had to go elsewhere for PPV, they were less likely to receive it. Referral of patients to the health department for immunizations, even those with third party payers such as Medicare, might be related to reimbursement levels for vaccination or to the time and effort required to complete insurance forms. The National Vaccine Advisory Committee reported that neglect of a reimbursement system for adult vaccination is a barrier. ${ }^{14}$ Although Medicare currently reimburses providers for the cost of administering PPV, it is important that reimbursement levels keep pace with costs to encourage vaccination within the adult patient's medical home. The costs include not only the rising costs of vaccine but also administration expenses, including injection supplies, nurse time, and billing costs. Further, streamlined methods for recovering costs of administering PPV might reduce the time and energy associated with completion of insurance forms and enable physicians to manage their practices better, leaving more time to devote to preventive services such as immunizations. One method is roster billing, which is frequently used during express immunization clinics and is allowed by Medicare.

Another option might be a federally funded adult vaccine program modeled after the Vaccines for Children Program (VFC). The VFC provides free vaccines directly to providers for eligible children, who are not billed, thus eliminating reimbursement issues. Furthermore, the VFC has been found to decrease physician referrals to public vaccine clinics and to decrease doses actually administered in public clinics in the context of increasing childhood immunization rates that have obtained record highs. ${ }^{15-19}$

\section{Strengths and Limitations}

Physicians represented a wide variety of practice types and settings and demographic characteristics. We also had large number of patients from a variety of socioeconomic levels and geographic regions who reported their PPV status.

A possible limitation is the use of self-report of patient immunization status, although self-report of pneumonia status has been used in national surveys, such as the Behavioral Risk Factor Surveillance System. ${ }^{20}$ In a published report, the sensitivity of selfreport of pneumococcal vaccination compared with chart audit ranged from $90 \%$ to $97 \%$ and the specificity ranged from $53 \%$ to $64 \% .^{21}$ In another part of our multicomponent study, the sensitivity of patient report compared with medical record review for pneumococcal vaccination was $85 \%$ (95\% confidence interval [CI], $82 \%-89 \%)$ and the specificity was $46 \%$ (95\% CI, $42 \%-50 \%) .{ }^{22}$

Although it is possible that the timing of the physician interviews and questionnaires administered during the 1999 influenza season might have influenced behavior, we believe from anecdotal evidence that physicians' views on immunizations and other aspects of their practices were well established and not particularly subject to change as a result of being interviewed.

Our results are not generalizable to the entire United States; our purpose was to establish a more detailed understanding of which physician and office factors are associated with immunization status.

\section{CONCLUSIONS}

Physicians in our study were aware of, agreed with, and have adopted and adhere to PPV recommendations. Physician barriers to vaccination were environmental issues related to referral for immunizations and managing the practice. Vaccination rates for pneumococcal disease might be improved through efforts that reduce likelihood of referral for immunizations and office systems that support immunization, such as patient and provider reminders and express vaccination clinics.

To read commentaries or to post a response to this article, see the online version at http:/lannfammed/cgi/content/full/2/1/41.

Key words: Pneumococcal polysaccharide vaccines; physicians; knowledge, attitudes, practice; aged

Submitted August 20, 2002; submitted, revised, November 27, 2002; accepted December 9, 2002.

Funding support: This project/publication was funded by HS0987401A1 from the Agency for Healthcare Research and Quality. 


\section{References}

1. Minino AM, Arias E, Kochanek KD, Murphy SL, Smith BL. Deaths: final data for 2000. Natl Vital Stat Rep. 2002;50:1-119.

2. Centers for Disease Control and Prevention. Early release of selected estimates based on data from the first quarter of 2002 NHIS. Available at: http://www.cdc.gov/nchs/about/major/nhis/ released200209.htm Accessed March 1, 2002.

3. US Department of Health and Human Services. Healthy People 2010 Conference Edition. 2nd ed. Washington, DC: US Department of Health and Human Services; 2000.

4. Medicare and medicaid programs; conditions of participation: immunization standards for hospitals, long-term care facilities, and home health agencies: final rule with comment period. Fed Regist. 2002;67:61808-61814.

5. Santibanez TA, Nowalk MP, Zimmerman RK, et al. Knowledge and beliefs about influenza, pneumococcal disease, and immunizations among the elderly. J Am Geriatr Soc. 2002;50:1711-1716.

6. Zimmerman RK, Santibanez TA, Fine MJ, et al. Barriers and facilitators of pneumococcal vaccination among the elderly. Vaccine. 2003;21:1510-1517.

7. Centers for Disease Control and Prevention. Adult immunization: knowledge, attitudes, and practices-DeKalb and Fulton Counties, Georgia, 1988. MMWR Morb Mortal Wkly Rep. 1988;37:657-661.

8. Mieczkowski TA, Wilson SA. Adult pneumococcal vaccination: a review of physician and patient barriers. Vaccine. 2002;20:1383-1392.

9. Gielen AC, McDonald EM. The PRECEDE-PROCEED planning model. In: Glanz K, Lewis FM, Rimer BK, eds. Health Behavior and Health Education: Theory, Research, and Practice. San Francisco, Calif: Jossey-Bass; 1997:359-383.

10. Pathman DE, Konrad TR, Freed GL, Freeman VA, Koch GG. The awareness-to-adherence model of the steps to clinical guideline compliance. The case of pediatric vaccine recommendations. Med Care. 1996;34:873-889.

11. Zimmerman RK, Santibanez TA, Janosky JE, et al. What influences older patients' influenza vaccination behavior? An analysis from inner-city, suburban, rural, and veterans affairs practices. Am J Med. 2003; 114:31-38.
12. Aday LA. Designing and Conducting Health Surveys: A Comprehensive Guide. San Francisco, Calif: Jossey-Bass; 1989.

13. Zimmerman RK, Silverman M, Janosky JE, et al. A comprehensive investigation of barriers to adult immunization: a methods paper. J Fam Pract. 2001;50:703.

14. National Vaccine Advisory Committee. Adult Immunization: A Report by the National Vaccine Advisory Committee. Washington, DC: US Department of Health and Human Services; 1994.

15. Zimmerman RK, Mieczkowski TA, Mainzer HM, et al. Effect of the Vaccines for Children program on physician referral of children to public vaccine clinics: a pre-post comparison. Pediatrics. 2001;108: 297-304.

16. Zimmerman RK, Medsger AR, Ricci EM, Raymund M, Mieczkowski TA, Grufferman S. Impact of free vaccine and insurance status on physician referral of children to public vaccine clinics. JAMA. 1997; 278:996-1000.

17. Szilagyi PG, Humiston SG, Shone LP, Barth R, Kolasa MS, Rodewald LE. Impact of vaccine financing on vaccinations delivered by health department clinics. Am J Public Health. 2000;90:739-745.

18. Szilagyi PG, Humiston SG, Shone LP, Kolasa MS, Rodewald LE. Decline in physician referrals to health department clinics for immunizations: the role of vaccine financing. Am J Prev Med. 2000;18:318 324.

19. Zimmerman RK, Nowalk MP, Mieczkowski TA, Mainzer HM, Jewell IK, Raymund M. The Vaccines for Children program: policies, satisfaction and vaccine delivery. Am J Prev Med. 2001;21:243-249.

20. Centers for Disease Control and Prevention. Behavioral risk factor surveillance survey. Available at: http://www cdc gov/nccdphp/BRFSS 2001.

21. MacDonald R, Baken L, Nelson A, Nichol KL. Validation of self-report of influenza and pneumococcal vaccination status in elderly outpatients. Am J Prev Med. 1999;16:173-177.

22. Zimmerman RK, Raymund M, Janosky JE, Nowalk MP, Fine MJ Sensitivity and specificity of patient self-report of influenza and pneumococcal polysaccharide vaccinations among elderly outpatients in diverse patient care strata. Vaccine. 2003;21:1486-1491. 